\title{
Factors that influence the quality constant of the manufacturing process for asphalt milling knifes
}

\author{
Daniela Maria Iovanas, ${ }^{1, *}$, Horia Binchiciu ${ }^{2}$, Ionelia Voiculescu ${ }^{3}$ and Emilia Florina \\ Binchiciu $^{2}$ \\ ${ }^{1}$ Transilvania University of Brasov, Department of Materials Engineering and Welding, 1 Colinei \\ Street, 500084 Brasov, Romania \\ ${ }^{2}$ SC Sudotim AS SRL Timisoara, 30 Mihai Viteazu Street, 300222 Timisoara, Romania \\ ${ }^{3}$ University POLITEHNICA of Buchares, Department of Materials Technology and Welding, 313 \\ Splaiul Independentei Street, 060042, Bucharest, Romania
}

\begin{abstract}
The quality constant for mill knifes used to strip asphalt is significantly influenced by the quality of the reinforcement which, in its turn, is influenced by the thermic brazing process and by manufacturing the protection system at blockage through welding when it spins around its axis. It's also influenced by the quality of the intelligent wear and blocking self-protection systems that in their turn are influenced by oxidation and diffusion processes of $\mathrm{W}$ and $\mathrm{C}$ that make simmered carbides from the reinforcement and brazed joints. Overheating during welding and brazing of the knife reinforcement and/or blockage self-protection reinforcement favours the oxidation of the $\mathrm{W}$ carbides leading to a fast degradation of the affected zones, even in exploitation. Exceeding optimum temperature during brazing of the reinforcement in the low chromium alloyed steel support leads to $\mathrm{Zn}$ evaporation in certain areas from the brazing material and lowers the brazed joint resistance to wear this causes the knife reinforcement to detach from the support. Taking into consideration the above mentioned facts it is recommended that the production stages of the mill knifes are done mechanized and/or automatic constantly monitoring the execution parameters.
\end{abstract}

\section{Basic aspect}

The above mentioned method is an experiment developed at Sudotim and it is a worldwide novelty.

The research objective, that of obtaining better asphalt cutting mill knifes and their manufacturing process, was reached by equipping the knife support with an intelligent protection system to self-locking when the knife is spinning [1-5], figure 1, around its own axis and that of implementing in the simmered tungsten carbide reinforcement the wear self-protection system, made from rhomb grids by melting with laser bean $[1-3,6]$.

* Corresponding authors: daniela.iovanas@yahoo.com 
The technical-scientific difficulties are those generated to assure a quality constant:

- Composite deposition from the self-locking system when spinning;

- Deep joint brazing with technical-mechanical constraint between the simmered tungsten carbide reinforcement and the low alloyed with chromium steel support;

- The laser bean melting technology needs to be without flaw at oxidation and/or vaporizing the rhomb grid that consolidates the reinforcement on the tip of the cutting knife.

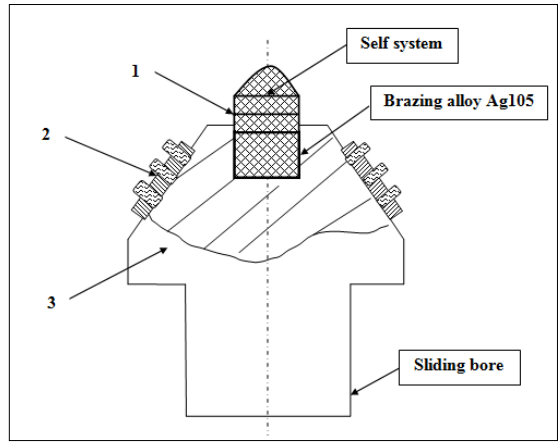

a)

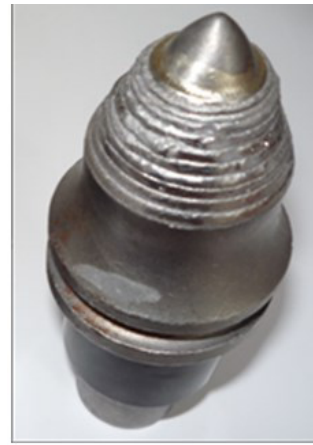

b)

Fig. 1. Mill asphalt cutting knife.

a) constitutive parts [2], b) assemble; 1-reinforcement-cutting body with self-protection at wear, 2-knife support made from low allowed steel with chromium, 3-self-locking when spinning system.

\section{Experiments to develop the protection system when self- locking at spinning}

Knife supports, developed in two ways, by casting or by forging, are characterized by:

- Chemical composition, Table 1, [3];

Table 1. The supports chemical composition.

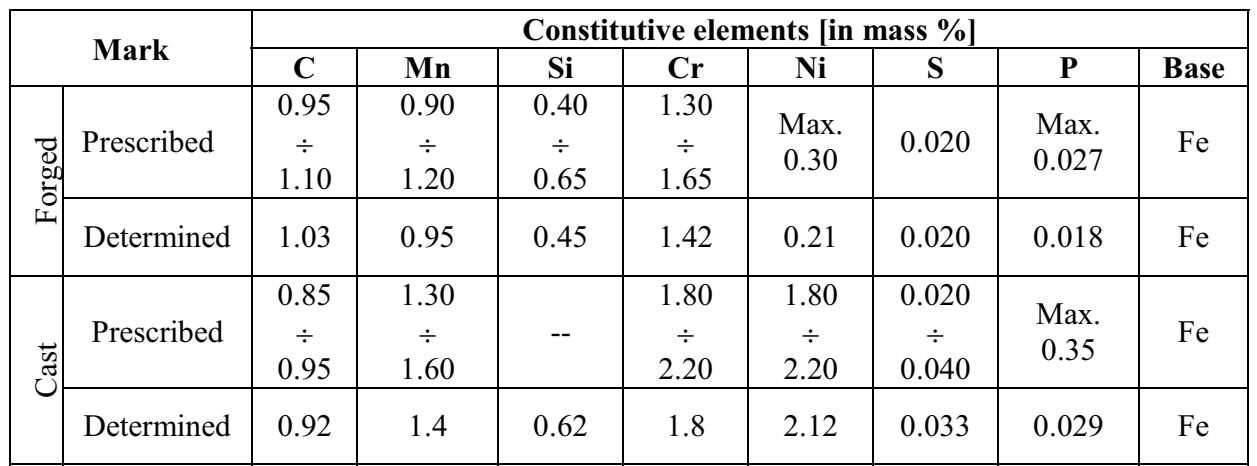

- Structural and sclerometric characteristics of the material. The supports hardness is changed during their manufacturing process, determined by softening thermal treatments and by enhancing mechanical processing at final odds;

- Precise geometric configuration. 
The self-protection to spinning system is characterised by:

- The welding behaviour of the addition material at welding;

- Matrix structure and reinforcement morphology;

- Configuration and thickness of the deposited layers.

Depositing the self-locking to spinning system was done using MIG [3] process, Fig. 2.
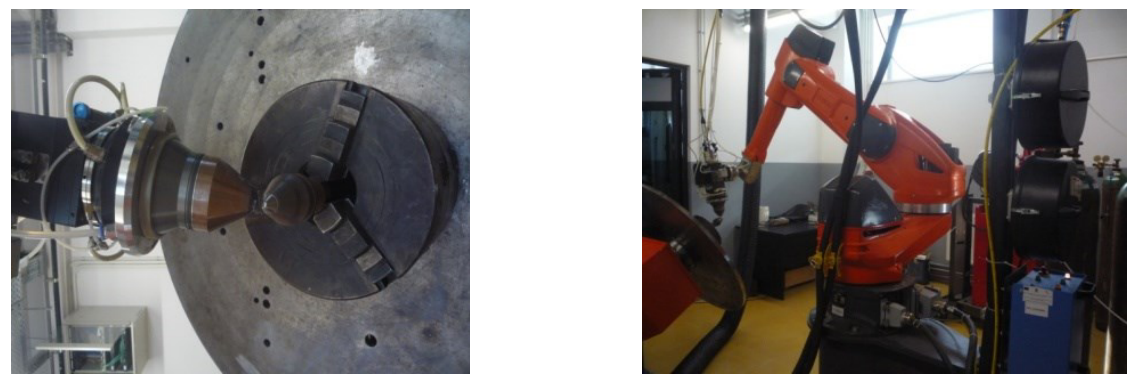

Fig. 2. MIG deposit using tubular wire.

Additional material (AD) is flux cored wire with composition: ST Fe-25\%W-4\%Cr used for welding with MIG process deposits thin layers of alloy type $\mathrm{Fe}-25 \% \mathrm{~W}-4 \% \mathrm{Cr}$ $\mathrm{Ti}$, rich in complex carbides, needle like [3]. The deposited layers have a harsh aspect and a high resistance to abrasion combined with corrosion and thermo-mechanical wear.

Chemical composition (Table 2), micro-structure (Fig. 3), and micro-hardness measured values (Base Material - BM, Heat Affected Zone - HAZ, Deposited Material - DM), (Table 3 ), of the deposited material using MIG procedure on a carbon steel plate fit into standard SF-SDT 14/2016, [7]. The tungsten deviation is explained by the fact that the carbides inside the reinforcement contain most of the tungsten.

Table 2. Chemical composition of the deposited metal (DM).

\begin{tabular}{|c|c|c|c|c|c|c|}
\hline Prescribed & $\mathbf{0 . 7 - 1 . 2 \% C}$ & $\mathbf{\sim 0 . 7 \% M n}$ & $\mathbf{m a x . 0 . 7 \% S i}$ & $\mathbf{3 . 5 - 4 . 5 \% C r}$ & $\sim \mathbf{2 5 \% W}$ & $\mathbf{\sim 0 . 3 \% T i}$ \\
\hline $\begin{array}{c}\text { Spectral } \\
\text { determined }\end{array}$ & 0.9 & 0.65 & 0.35 & 4.2 & 12.8 & 0.35 \\
\hline
\end{tabular}

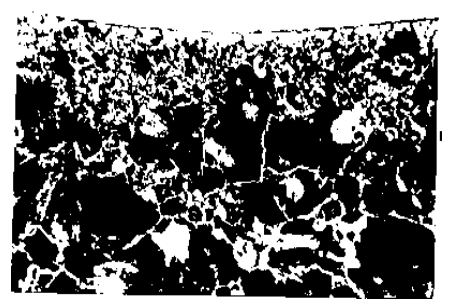

Fig. 3. Deposited metal micro-structure, nitric attack $2 \%-25 \mathrm{sec}, \mathrm{X} 500$, dendritic structure, uneven.

Table 3. Micro-hardness measured values.

\begin{tabular}{|c|c|c|}
\hline \multicolumn{3}{|c|}{ Measured points values HV 0.2} \\
\hline BM & HAZ & DM \\
\hline $402 ; 410 ; 415$ & $365 ; 372 ; 353$ & $535 ; 544 ; 565-$ on matric \\
$1200 ; 1135 ; 1208-$ on carbides \\
\hline
\end{tabular}




\section{Experiments to qualify the brazing process}

The brazed joint, support-tungsten carbide (WC) reinforcement, is characterized by the chemical-physical proprieties of the addition material and by the manufacturing process of the joints, prescribed by the execution procedure in order to assure constant quality [8-9].

The thermal dilution coefficient of the support, made from the above presented steels, is available with temperatures between the interval 12, 19...19.4x106 [1/grd.], at temperatures from $0^{\circ} \mathrm{C}$ to $1200^{\circ} \mathrm{C}$.

The reinforcement used in both situations is from the hard alloys category, made by powder metallurgy, type VC-TiC-Co. For testing we used tips from the category P30, characteristics are presented in Table 4, in a non-affected thermal state. We used the above mentioned taking into account resistance to bending and cost.

Table 4. Alloy proprieties VC-TiC-Co.

\begin{tabular}{|c|c|c|c|c|c|c|c|}
\hline \multirow{2}{*}{ Group } & \multicolumn{3}{|c|}{$\begin{array}{c}\text { Chemical } \\
\text { composition [\%] }\end{array}$} & \multicolumn{3}{c|}{ Medium values of the chemical- physical characteristics } \\
\cline { 2 - 8 } & WC & TiC & Co & $\begin{array}{c}\text { Hardness } \\
\mathbf{H V} \\
{\left[\mathbf{d a N} / \mathbf{m m}^{2}\right]}\end{array}$ & $\begin{array}{c}\text { Bending } \\
\text { resistance } \\
{\left[\mathbf{N} / \mathbf{m m}^{2}\right]}\end{array}$ & $\begin{array}{c}\text { Compression } \\
\text { resistance } \\
{\left[\mathbf{N} / \mathbf{m m}^{2}\right]}\end{array}$ & $\begin{array}{c}\text { Thermal dilution } \\
\text { coefficient } \\
\mathbf{x 1 0}^{\mathbf{6}}[\mathbf{1} / \mathbf{g r d}]\end{array}$ \\
\hline $\mathrm{P} 30$ & 82 & 8 & 10 & 1500 & 1700 & 5000 & 5.5 \\
\hline
\end{tabular}

Technical characteristics provided by material manufacturers and those determined by experiments highlight the framing in prescriptions.

Physical-chemical and structural characteristics of the addition material, mark VIAg40SnR, [3, 7], are shown in Table 5, 6 and figure 4.

Table 5. Chemical composition of the constituents used to make VIAg40SnR.

\begin{tabular}{|c|c|c|c|c|c|}
\hline \multirow{2}{*}{ Code } & \multicolumn{5}{|c|}{ Composition [mass \%] } \\
\cline { 2 - 6 } & $\mathbf{A g}$ & $\mathbf{C u}$ & $\mathbf{Z n}$ & $\mathbf{S n}$ & $\mathbf{S i}$ \\
\hline MDVIAg40SnR & 40.3 & 30.2 & 26.1 & 2.4 & 0.05 \\
\hline
\end{tabular}

Table 6. Hardness valued determined on the deposited material using VIAg40SnR.

\begin{tabular}{|c|c|c|}
\hline Hardness value HB/DM & Micro-hardness VICKERS-HV ..1 $_{\mathbf{D}} \mathbf{\text { DM }}$ & Average value \\
\hline $185 ; 190 ; 183 ; 188 ; 189$ & $208 ; 206 ; 212 ; 215 ; 210$ & $187 \mathrm{HB}$ \\
& Measuring uncertainty: $2.14 \%$ & $210.2 \mathrm{HV}_{0.1}$ \\
\hline
\end{tabular}

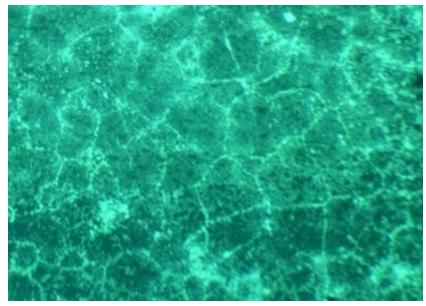

a)

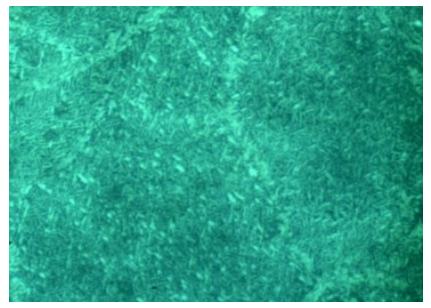

b)

Fig. 4. Structural characteristics of the deposited material using VIAg40SnR, a) 100X, b) 500X.

Sclerometric results confirm detected structures and chemical composition on the deposited material.

Joint design, fig. 1, was determined on the principle of developing capillary joint, which have a high resistance to wear by abrasion under high pressure and reduced costs. To this end we choose a joint of $0.1 \div 0.15 \mathrm{~mm}$, made by mechanical processing. Parts positioning, 
in order to start brazing, were done after examining the brazing surface and that of the remains left after processing. Checking the geometric constant of the joint was done by calibrating, thickness $0.1 \mathrm{~mm}$. In order to heat and deposit the addition material into the joint, we choose a nozzle and adjust the oxy-acetylene flame character. To avoid losing carbides and reinforcement oxidation when heating, we used a carbide flame and a protection for the reinforced tip made from a mixture of graphite and alumina and sodium silicon, dried and burnt.

Deposition temperature for the addition material in deep joint measured with pyrometer with laser bean was $625 \div 780^{\circ} \mathrm{C}$. Thus obtained joint was cleaned by brushing and activated by washing with water and activating solution.

We extracted samples from the accomplished joint in order to characterise the product, by destructive and non-destructive testes, according to SR EN 13134:2002. Results were subjected to visual examination in two stages, unfinished state and end product (according to SR EN 12799:2002).

Metallographic results of the joints at the passing zone of the addition material and knife support, influenced by the brazing process, are highlighted below, Fig. 5 .

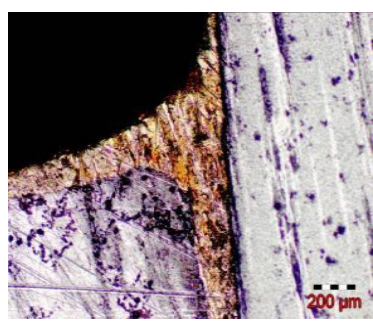

a)

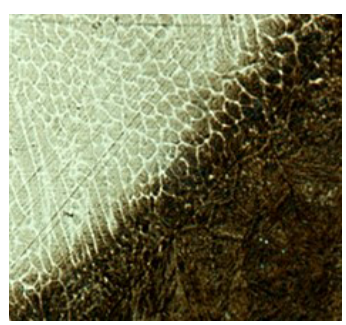

b)

Fig. 5. Macro-micrographic analysis of the joining zone in cross section, a) macroscopic aspect of knife support-carbide (20X); b) microscopic aspect addition material-carbide (100X).

We can observe a good diffusion of the addition material into the base material $(\mathrm{BM})$, also changes like reduced grain size of the recurrence structure of the base material in the adjacent area of the addition material. These phenomena can be explained by overlapping the thermal effect produced at brazing with the one from the recurrence one of the support.

Metallographic analysis was accompanied by hardness determinations, using Vickers method, (Table 7).

Table 7. Hardness test results (HV0.1).

\begin{tabular}{|c|c|c|c|c|c|}
\hline Test area & $\begin{array}{c}\text { MB } \\
\text { support }\end{array}$ & $\begin{array}{c}\text { HAZ } \\
\text { support }\end{array}$ & AM & WC & Matric \\
\hline \multirow{2}{*}{$\begin{array}{c}\text { Micro-hardness } \\
\text { Vickers HV0.1 }\end{array}$} & 680 & 550 & 160 & 1480 & 352 \\
\cline { 2 - 6 } & 700 & 515 & 160 & 1560 & 339 \\
\cline { 2 - 6 } & 710 & 535 & 181 & 1410 & 351 \\
\hline
\end{tabular}

Hardness structures confirm detected structures. Results obtain on tungsten carbide constituents show a decrease of $1 \%$. Hardness decrease is insignificant in concrete industrial situations.

Conducted tests validate the brazing process and justifies it's qualification proposal, according to SR EN 13134:2002. 


\section{Experiments to determine the melted grid on the tip the reinforcement-cutting knife, using laser bean}

The self-protection system to wear is characterised thus:

- By the reinforcement quality;

- By the constant quality of the melting process of the grid;

- By geometrical parameters of the grid.

Work parameters and their values are presented in Table 8, [1].

Table 8. Work parameters.

\begin{tabular}{|c|c|c|c|}
\hline \multirow{2}{*}{ Work parameters } & \multicolumn{3}{|c|}{ Work parameters value } \\
\cline { 2 - 4 } & $\mathbf{1}$ & $\mathbf{2}$ & $\mathbf{3}$ \\
\hline Focalize [mm] & 5 & 5 & 5 \\
\hline Movement speed [mm/s] & 1 & 1.5 & 2 \\
\hline Pulse frequency [Hz] & 6633.100 & 6633.100 & 6633.100 \\
\hline Distance between impulses [mm] & 0.05 & 0.05 & 0.05 \\
\hline Welding time [min] & 24 & 20 & 16 \\
\hline
\end{tabular}

To analyse micro-hardness characteristics we made measuring on the external surfaces of the reinforcement-cutting tip, using Vickers method.

Micro-hardness values reinforcement tip-cutting body before laser processing are shown in Table 9, and the ones measured on the laser processed surfaces in Table 10, with the remark that values that are below average can be explained by the fact that the diamond tip had excess binder in some areas.

Table 9. Micro-hardness values determined on the tip of the reinforcement-cutting body made from tungsten carbide before laser processing.

\begin{tabular}{|c|c|}
\hline Measured values, $\mathbf{H V}_{\mathbf{0 . 2}}$ & Average value, $\mathbf{H V}_{\mathbf{0 . 2}}$ \\
\hline $873 ; 1102 ; 910 ; 1124 ; 1128 ; 1191 ; 1151 ; 1456 ; 890 ; 1143$ & 1092 \\
\hline
\end{tabular}

Table 10. Micro-hardness values HV 0.2 determined on reinforcement tip - cutting body made from tungsten carbide after laser processing.

\begin{tabular}{|c|c|c|}
\hline Measuring area & Measured values, $\mathbf{H V}_{\mathbf{0 . 2}}$ & Average value, $\mathbf{H V}_{\mathbf{0 . 2}}$ \\
\hline 1 & $1273 ; 1357 ; 1426 ; 1134 ; 1088$ & 1256 \\
\hline 2 & $1221 ; 1220 ; 1284 ; 1305 ; 1189$ & 1244 \\
\hline 3 & $1381 ; 1244 ; 1052 ; 1039 ; 1399$ & 1223 \\
\hline
\end{tabular}

Micro-structural analysis was made by electronic microscopy SEM, they can be observed in Fig. 6. The image presents micro-structural aspects of the tungsten carbides for areas 1,2 and 3. After laser processing we can clearly observe melted areas under the lasers action.

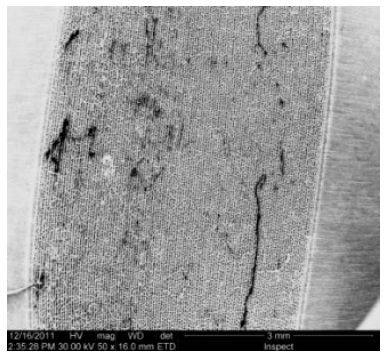

a)

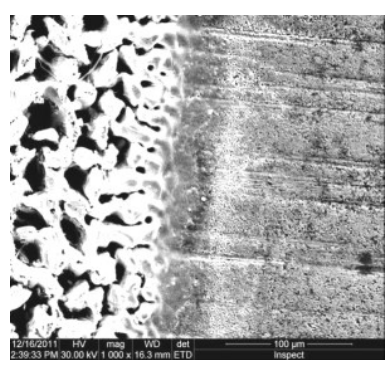

b)

Fig. 6. SEM analysis images of the specific areas, a) crack due to a major energetic impact on the melted grid, b) passing area. 
In figure 7, on area 3 we can notice micro-cracks developed from the melted area and the forming of a melted crust with length of approximately $45 \mu \mathrm{m}$, which in exploitation determines the reinforcements degradation.

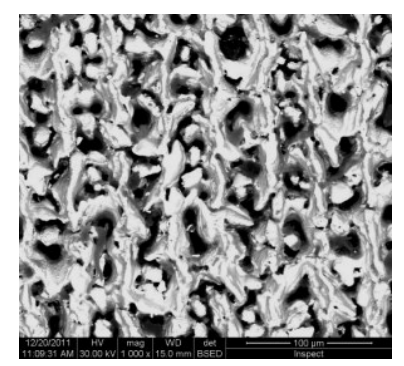

Fig. 7. Micro-crack area, growth 1000X.

\section{Conclusions}

The solution for implementing in production consists of:

$>$ Developing the reinforcement tip, by simmering tungsten carbides, and the tooth support, made of low alloyed steel with chromium, by casting or precision forging;

$>$ Loading by welding, with harsh deposits, of the knife support in its conical area;

$>$ Brazing the reinforcement tip in holes in the body of the knife support.

Applying the solution imposes solving the following problems:

$>$ discharging or reducing the loss of carbides and/or that of corrosion by oxidation of the reinforcement under the action of heat when brazing;

$>$ Assuring compatibility at brazing, with oxy-acetylene flame, of the base materials with the addition ones, in intense conditions of the cycle efforts of dilution and contraction of the tooth support, of the reinforcement at brazing and when depositing the joining layers;

$>$ Assuring the joint removal temperature, superior to that of the brazed ensemble, when developing the joint.

\section{References}

1. R.F. Iovanas, Theoretical and experimental research on increasing the durability and reliability of equipments, manufactured by weld cladding, visible on earth drilling equipments, $(\mathrm{PhD}$ thesis, Universitatea Transilvania din Brasov, Brasov, Romania, 2012)

2. E.F. Binchiciu, V. Geanta, I. Voiculescu, R. Stefanoiu, R. F. Iovanas, A. Binchiciu, H. Binchiciu, Cutit de freza pentru decopertat asfalt cu sistem de autoprotectie la uzare si autoblocare la rotire si procedeu de fabricatie, (RO Patent 129863, 2014)

3. ***, http://www.matfrez.ro/, accessed 1.02.2017

4. T. D. Tanasache, C. Florea, V. Geanta, E. Binchiciu, AMR, 1029, 78 (2014)

5. C. Buzatu, A.-E Dumitraşcu., D.I., Dumitraşcu, I. Orzan I., AMM, Eng. Sol. and Techno. in Manuf., 657, 48 (2014)

6. R. F. Iovanas, D. M. Iovanas, I. Voiculescu, N. I. Trif, Metalurgia, J, 4, 20 (2012)

7. ***, www.sudotim.ro, accessed 11.02.2017

8. E. Binchiciu,T. Fleser, I. Voiculescu, AMR, 1029, 72 (2014)

9. E.F. Binchiciu, Integrated brazing technologies with advance precursors (PhD thesis, Universitatea Politehnica Timisoara, Romania, 2016) 